\title{
Trabalho, Vagabundagem E ANTICAPITALISMO: ENSAIO SOBRE A SOCIOLOGIA INCONFORMISTA DE JACK LONDON
}

\section{Lúcio Vasconcellos de VERÇOZA*}

\begin{abstract}
RESUMO: A obra de Jack London é atravessada pelo percurso de sua experiência viva de criança operária, pirata de água doce, vagabundo nômade, militante socialista e de tantas outras controversas facetas do que ele foi. Esses temas são recorrentes em seus escritos. Este ensaio investiga como London aborda algumas dessas temáticas e sugere que em seus contos a arte literária se confunde com uma forma insólita de sociologia.
\end{abstract}

PALAVRAS-CHAVE: Arte Literária. Sociologia. Anticapitalismo.

Notas introdutórias

De vez em quando, em jornais, revistas e enciclopédias biográficas, leio esboços da minha vida nos quais, em frases polidas, dizem que foi para estudar sociologia que me tornei um vagabundo. É algo muito gentil e perspicaz da parte dos biógrafos, mas impreciso. Tornei-me um vadio por causa da vontade de viver dentro de mim, do desejo de aventura que corria em meu sangue e não me deixava descansar. A sociologia foi algo meramente acidental; veio depois, da mesma maneira que nos

\footnotetext{
SEUNE - Sociedade de Ensino Universitário do Nordeste. Faculdade de Direito. Maceió - AL - Brasil. 13565905 - luciovercoza@yahoo.com.br
} 
molhamos depois de um mergulho na água. Peguei a estrada porque não conseguia ficar longe dela; porque não tinha um tostão no bolso para pagar por uma passagem de trem; porque não queria fazer a mesma coisa a vida inteira; ora, apenas porque era mais fácil do que não me aventurar (LONDON, 2008a, p. 143).

No prefácio de Carta ao pai de Franz Kafka (2004), Marcelo Bakers (2004, p. 11), sugere que "em vez de interpretar a obra [Carta ao Pai] a partir do complexo de Édipo, no entanto, o mais interessante talvez fosse interpretar o complexo de Édipo a partir da obra". Essa provocante proposta de inversão metodológica em relação ao livro de Kafka possivelmente é válida também para os contos de Jack London. Porém, no caso do escritor estadunidense, não se trata de interpretar o complexo de Édipo, mas a complexidade social vista a partir do fundo do abismo, do porão da sociedade.

Esse itinerário de inversão metodológica, que norteia o presente ensaio, leva aos pontos de cruzamento entre a arte literária e a sociologia, aos lugares fronteiriços ou de diluição dos limites que separam a escrita literária da escrita sociológica. Leva ainda à busca pelas pegadas do errante autor de Caninos Brancos (2001), aos rastros que possam contribuir para a compreensão dos sentidos de seus textos e para o desvelamento da realidade social.

\section{A vida e o anticapitalismo de Jack London}

Os contos do insubordinado autor de $O$ tacão de ferro (LONDON, 2002) são marcados pelo forte caráter autobiográfico. Por isso, sublinhar brevemente alguns traços gerais de sua vida, mais do que mera introdução, tem relação direta com a busca pelo chão que ancora seus textos. Para tal, nada melhor do que começar com próprio London (2008b) falando sobre si, no conto O que a vida significa para mim:

Nasci na classe trabalhadora. Cedo descobri o entusiasmo, a ambição e os ideais; e satisfazê-los tornou-se o problema da minha infância. [...]. Mas não é fácil para um homem ascender e sair da classe trabalhadora - especialmente se está cheio de ambições e ideais. [...]. Aos dez anos de idade, tornei-me jornaleiro nas ruas da cidade e descobri uma nova perspectiva [a dos negócios]. [...] Quando tinha dezesseis anos me chamavam de 'príncipe'. Este título me foi dado por uma gangue de assassinos e ladrões, que me chamavam de 'O Príncipe dos Piratas 


\section{Trabalho, vagabundagem e anticapitalismo: ensaio sobre a sociologia inconformista de Jack London}

de Água Doce'. Naquele tempo eu tinha galgado o primeiro degrau no mundo dos negócios. Era um capitalista. Possuía um barco e uma tripulação completa de piratas de água doce. [...]. Este degrau foi o último que subi no mundo dos negócios [pois seu barco fora roubado] [...] Desde então fui implacavelmente explorado por outros capitalistas. [...]. Fui marinheiro, estivador e grumete. Trabalhei em fábricas de enlatados, indústria e lavanderias. Cortei grama, limpei tapetes e lavei janelas. [...] $\mathrm{O}$ excesso de trabalho me deixou doente. Eu não queria mais ver trabalho. Abandonei o emprego. Tornei-me um vagabundo, mendigando de porta em porta, perambulando pelos Estados Unidos e suando sangue em favelas e prisões. Eu nascera na classe operária, e agora, aos dezoito anos, estava abaixo do ponto em que tinha começado. [...]. Estava apavorado até a alma. Via a nu a complicada civilização em que vivia. A vida era uma questão de abrigo e de comida. Para conseguir abrigo e comida os homens vendem coisas[...]. Aprendi, ainda, que o cérebro também é uma mercadoria ainda que diferente dos músculos. [...]. Começou então uma frenética perseguição ao conhecimento. Voltei para a Califórnia e mergulhei nos livros. Como me preparava para ser um mercador de inteligência, achei que devia me aprofundar em Sociologia. [...] Como mercador da inteligência, fui um sucesso. A sociedade abriu suas portas para mim. Entrei direto no andar de luxo; mas meu desencanto foi rápido[...]. Percebi que não gostava de viver no andar de luxo da sociedade. Intelectualmente era aborrecido. Moralmente e espiritualmente, eu me sentia enjoado[...]. Então, voltei à classe operária, na qual havia nascido e à qual pertencia. Não me preocupava mais em subir. O imponente edifício da sociedade não reserva delícias para mim acima de minha cabeça. São os alicerces do edifício que me interessam[...]. Esta é a minha perspectiva. Vejo à frente um tempo em que o homem deverá caminhar para alguma coisa mais valiosa e mais elevada do que seu estômago, quando haverá maiores estímulos para levar o homem à ação do que o incentivo de hoje, que é o incentivo do estômago. (LONDON, 2008b, p. 17- 27)

Ainda que Bourdieu (2006) alerte sobre o risco de nos conformarmos com uma ilusão biográfica, quando se trata de narrativa de história de vida - pois o narrador é propenso a dar coerência e sentido lógico a acontecimentos que na maioria das vezes foram incoerentes e influenciados pela submersa camada do inconsciente-, achamos válido transcrever essa longa citação, porque nela estão contidos aspectos da vida de London que transbordam em seus contos. Podemos destacar ao menos três eixos: 1) trabalho; 2) vagabundagem; 3) crítica ao capitalismo. Como Jack London aborda essas temáticas é algo que nos interessa, entretanto cabe antes caracterizar melhor sua vida à luz do contexto histórico da época. 
Jack London nasceu em janeiro de 1876, em São Francisco, Califórnia, e nunca chegou a conhecer o pai biológico. Oito meses após o seu nascimento, sua mãe casou-se com um agricultor, por isso, quando criança, morou por três anos em um rancho - em condições paupérrimas, chegando até a passar fome. Depois residiu na cidade de Oakland e encontrou muitas dificuldades para concluir a educação básica devido à falta de dinheiro. Nessas circunstâncias, antes de completar dezesseis anos de idade, foi obrigado a trabalhar como:

Entregador de jornais, faxineiro, arrumador de pinos de boliche e, depois, numa fábrica de enlatados, a Hickmott's Cannery, na rua Myrtle (na parte oeste da cidade), um antigo estábulo abandonado, insalubre, onde crianças costumavam suar a camisa por pelo menos dez horas por dia, a dez centavos a hora. A jornada laboral de Jack, contudo, era ainda mais longa, em média quatorze horas diárias (ele chegou, certa vez, a operar sua máquina por 36 horas seguidas, sem descanso). Todo salário que ganhava ia para a mãe e o padrasto (PERICÁS, 2008, p.12).

O trabalho aviltante e degradante é um tema que aparece com certa recorrência em seus contos. Mais especificamente no caso da experiência de labor infantil, o conto O Herege (LONDON, 2008c), que retrata o cotidiano de uma criança operária, traz à tona como o trabalho pode consumir a vida na mais tenra idade. Esse texto, que se transfigurou em arma nas mãos dos movimentos pela abolição do trabalho infantil nos Estados Unidos, certamente foi motivado pelo que o escritor viveu e testemunhou nos tempos de menino.

Não é por acaso que no conto a criança esteja trabalhando em uma fábrica em vez do campo. A conjuntura em que London estava inserido (fim do século XIX e início do XX) foi marcada nos Estados Unidos pela abrupta intensificação da industrialização e urbanização. A própria trajetória pessoal do autor expressa esse processo: nasceu na fazenda, mas foi criado na periferia da cidade. London era parte da multidão de expropriados da terra. Os becos, as fábricas, as máquinas eram um mundo novo recém-parido. Como destaca Luís Bernardo Pericás (2008), Jack London muito provavelmente não teria levado temporariamente uma vida de vagabundo itinerante, cruzando clandestinamente os Estados Unidos, se não fosse pela extensa malha ferroviária que cobria o imenso território norte-americano. $\mathrm{O}$ autor destaca ainda que os "trens, de fato, tiveram uma importância singular no desenvolvimento da 'América' até o final do século XIX, perdendo sua força apenas muitas décadas depois” (PERICÁS, 2008, p. 10).

Jack London viveu em uma época de crescimento vertiginoso do espaço urbano e do trabalho fabril, mas sua obra não se restringe a esse universo. O cenário urbano de São Francisco do início do século XX é tão bem retratado no conto 


\section{Trabalho, vagabundagem e anticapitalismo: ensaio sobre a sociologia inconformista de Jack London}

Ao sul da fenda (2008d) - logo no início do texto é mencionada a fronteira invisível que divide a cidade ${ }^{1}$ - quanto as profundezas inóspitas do Alasca, no conto Fazer uma fogueira (2008e). Provavelmente, essa diversidade de cenários não se deve somente ao fato de ter sido um aventureiro (no melhor sentido da palavra), que dentre suas várias viagens, realizou expedições de barco até ilhas do Pacífico Sul e foi em busca de ouro nas montanhas geladas do Yukon. Talvez seu anticapitalismo, expresso claramente no conto Como me tornei socialista (2008f), em alguns momentos o levava a flertar com o mundo pré-capitalista.

No livro O chamado da floresta (1995), o autor conta a saga de um cachorro que aos poucos vai se desdomesticando, tornado-se selvagem, sendo essa história uma espécie de metáfora para emancipação. Ainda que as durezas da vida distante da urbe não sejam omitidas em seus escritos - o conto Amor à vida (2008g) que o diga -, existe neles uma tendência em considerar os confins da civilização não somente como um refúgio, mas também como uma espécie de alternativa.

A cidade nos contos de London aparece como ambiente mais carregado de atritos, pois se no rural arcaico ou no espaço não civilizado pode ser evidenciada a tensão entre o ser humano e a natureza, no ambiente urbano a natureza desaparece e a tensão entre os seres humanos ocorre de forma mais crua, sem direito sequer a caçar ou coletar sementes. Enquanto o universo rústico e selvagem é predominantemente retratado como local de atração, o urbano exerce constantemente atração e repulsa, encantamento e desencantamento. A atração pelo suposto não civilizado, pelo selvagem, claramente presente no livro O chamado da floresta (1995), talvez signifique a fuga ou a busca de superação da insuportável tensão entre os seres humanos.

Trata-se de algo um tanto diferente da tensão descrita por Simmel em A metrópole e a vida mental (1977). Enquanto o sociólogo alemão a coloca no plano da "reivindicação que faz o indivíduo preservar a autonomia e a individualidade de sua existência em face das esmagadoras forças sociais, da herança histórica, da cultura externa e da técnica da vida" (SIMMEL, 1977, p. 13), London destaca o caráter insuportável da tensão sobretudo no plano das classes sociais. Sua aposta contra a gula grosseira da sociabilidade capitalista estava tanto na luta de classes, quanto na doçura e no despojamento espiritual.

\footnotetext{
1 A cidade de São Francisco é apresentada da seguinte forma: "Ao norte da fenda ficavam os teatros, hotéis, os grandes armazéns, os bancos e as sólidas e respeitáveis casas de negócios. Ao sul amontoavam-se as fábricas, as vielas, as lavanderias, as oficinas, as caldeiras de aquecimento e os casebres dos operários. Essa fenda metafórica expressava a divisão da cidade em classes e ninguém transpunha a metáfora, para cá e para lá, com mais entusiasmo do que Freddie Drummond" (LONDON, 2008d, p. 113). É válido mencionar que o personagem Freddie Drumond era um sociólogo que pesquisava o sul da fenda.
} 
O urbano nos contos de London é atraente na medida em que se pode de alguma forma subverter a ordem, seja viajando milhares de quilômetros clandestinamente de trem e sem trabalhar (pingando de cidade em cidade), escrevendo textos críticos ao capitalismo ou participando das lutas sociais. Mas, logo aparecem os limites da subversão e com eles os desencantos: o vagabundo entrando no "abismo social", o escritor como "mercador de inteligência" e a luta de classes realizada em condições muito desfavoráveis para os trabalhadores. Por isso o urbano talvez assuma em seus textos o sentido de atração e repulsa, como também o seu flerte com o chamado selvagem, com um anticapitalismo que aponta para o retorno à terra, para os primórdios da humanidade.

Essa hipótese é fortalecida na carta que ele enviou ao seu editor, no contexto de forte embate e de defesa da liberdade criativa no ofício de escritor:

Insisto agora, como sempre insisti, que a virtude literária cardeal é a sinceridade. Se estou errado nesta convicção e o mundo me renega, só me cabe dizer um adeus indiferente ao mundo e orgulhoso refugiar-me no rancho, plantar batatas e criar galinhas para conservar o estômago cheio. Foi a minha recusa de aceitar advertências sensatas que me fez o que sou hoje (LONDON, Jack apud GEBRIM, 2008, p. 10).

\section{Da ética ascética do labor à fuga do trabalho duro}

No conto Como me tornei socialista (LONDON, 2008f), são descritas as suas visões de mundo em diferentes fases da sua vida:

Ser HOMEM significava escrever em letras maiúsculas no meu coração. Arriscarme como homem, lutar como homem, fazer o trabalho de homem (mesmo que com o salário de menino) - essas eram coisas que me tocavam profundamente $\mathrm{e}$ ficavam gravadas em mim como nenhuma outra. [...] A dignidade do trabalho era para mim a coisa mais impressionante do mundo. Sem ter lido Carlyle ou Kipling, formulei um evangelho do trabalho que varriam os deles 'no chinelo'. O trabalho era duro. Era a santificação ou salvação. O orgulho que sentia depois de um dia de trabalho árduo e bem feito seria algo incompreensível para os demais. É quase inconcebível para mim quando penso nisso agora. Nunca um capitalista explorou um escravo do salário tão fiel quanto eu. Embromar ou ludibriar o homem que me pagava era um pecado, primeiro contra mim mesmo, e depois contra ele. Para mim era um crime que vinha logo atrás da traição, mas não tão ruim quanto. (LONDON, 2008f, p. 30-31) 


\section{Trabalho, vagabundagem e anticapitalismo: ensaio sobre a sociologia inconformista de Jack London}

Nessa passagem, podemos compreender os significados do trabalho árduo durante a primeira fase da vida do autor. O labor significava virilidade e reforço da masculinidade, expresso no termo HOMEM com letras maiúsculas; significava ainda dignidade; conforto espiritual, presente na ideia de santificação ou salvação; elevação da autoestima externada no orgulho sentido após um dia de trabalho duro. Por outro lado, podemos compreender também o que significava para ele não trabalhar: enfraquecimento de sua masculinidade, perda de dignidade, punição no plano espiritual e rebaixamento da autoestima.

Muito provavelmente sem ter lido A ética protestante e o espírito do capitalismo (WEBER, 2004), London manifestou as motivações que o levavam a trabalhar arduamente a partir de uma perspectiva que lembra a abordagem weberiana $^{2}$. Ele não destacou nesse momento as condições objetivas que o levaram a vender a sua força de trabalho em longas jornadas laborais e de forma tão intensa, pelo contrário, na passagem acima, o trabalho árduo é apresentado sobretudo como uma atividade motivada por determinados valores morais. Se nessa passagem aparece alguma coerção que determina tal nível de carga laboral, ela está principalmente no âmbito da subjetividade de quem trabalha.

Mais adiante, o autor continua descrevendo a sua trajetória em relação ao trabalho da seguinte forma:

Por essa época, voltando de uma viagem que durara sete meses [trabalhando como marinheiro], e logo após ter completado dezoito anos de idade, pus na cabeça a ideia de que iria vagabundar. Em vagões de passageiros ou compartimentos de carga, desbravei meu caminho pela vasta região Oeste, onde os homens trabalham duro e os empregos procuram as pessoas, até os congestionados centros de operários da região Leste, onde os homens tinham pouco valor e davam o que tinham para conseguir trabalho. E nesta nova aventura de fera loura, comecei a ver a vida de um ângulo novo e totalmente diferente. Eu havia descido da condição de proletário para o que os sociólogos chamam de 'porção submersa', [...] Lá encontrei todo o tipo de homens, muitos dos quais haviam sido algum dia tão bons e tão feras louras quanto eu: marinheiros, soldados, operários, todos estropiados, comidos e desfigurados pelo trabalho, pelas agruras e pelos acidentes e dispensados por seus patrões como cavalos velhos. Com eles mendiguei nas ruas, pedi comida nas portas dos fundos das casas e senti frio em vagões de trens e parques da cidade, ouvindo as histórias de vida, que começavam sob auspícios tão favoráveis como os meus, com estômagos e corpos iguais ou melhores do

\footnotetext{
2 A primeira tradução de $A$ ética protestante e o espírito do capitalismo para o inglês foi realizada somente em 1930 (PIERUCCI, 2004), enquanto Jack London morreu anos antes, em 1916. É deveras improvável que ele tenha lido o texto original, em alemão.
} 
que os meus, e que terminavam ali, diante de meus olhos, arruinados, no fundo do Abismo Social. E enquanto eu ouvia, meu cérebro começava a funcionar. A mulher das ruas e o homem da sarjeta se tornaram muito próximos de mim. Vi a imagem do Abismo Social vividamente, como se fosse algo concreto. Eu os observava lá no fundo do abismo, um pouco acima deles, agarrando-me às paredes escorregadias com todo o suor e força de minhas unhas. E confesso que um medo terrível se apoderou de mim. Se acabasse minha força? E quando me tornasse incapaz de trabalhar lado a lado com os homens fortes que ainda estavam por nascer? (LONDON, 2008f, p. 31 e 32).

Nesse trecho, é descrita como se deu a ruptura com uma ética ascética do trabalho e seu período de transição do assalariamento desenfreado para a vagabundagem. No que diz respeito ao segundo momento, podemos perceber que o entusiasmo inicial com um modo de vida à deriva também foi rapidamente quebrado. Isso remete à discussão anterior acerca dos encantos enquanto possibilidades e os desencantos enquanto limites. Para London, a vagabundagem nômade inicialmente parecia ser um degrau acima quando comparada à condição proletária, todavia logo ele percebeu que era o inverso, a vida de vagabundo estava inserida no que denominou como "Abismo Social", que como o próprio nome já indica, poderia ser uma queda sem volta, e isso the causara um medo terrível.

Ele percebeu ainda que muitos daqueles que estavam no abismo foram no passado operários tão produtivos quanto ele, mas que com o tempo não tinham mais a mesma energia física e mental. Sem citar O Capital (MARX, 1989), que muito provavelmente ele conhecia, London expõe nessas linhas, em tom vivo de relato autobiográfico, a questão do desgaste prematuro da força de trabalho, tema que décadas mais tarde seria muito caro para os estudiosos da superexploração (MARINI, 2005). O risco iminente da perda prematura de suas energias vitais acarreta reviravolta na ética do trabalho do autor:

Aí, então, fiz um juramento. Era algo mais ou menos assim: Todos os dias tenho trabalhado até a exaustão com o meu corpo e apesar do número de dias que trabalhei, cheguei bem próximo do fundo do Abismo. Deverei sair dele, mas não com os músculos do meu corpo. Não vou nunca mais trabalhar como trabalhei e que Deus me fulmine se um dia eu der de mim mais do que o meu corpo pode dar. E desde então tenho me dedicado a fugir do trabalho duro (LONDON, 2008f, p. 32-33).

Esse processo de mudança na ética do trabalho descrito acima transparece também em outros textos de sua lavra. Neles a reificação atinge todo o edifício do 


\section{Trabalho, vagabundagem e anticapitalismo: ensaio sobre a sociologia inconformista de Jack London}

mundo capitalista: dos "povos do abismo" ao andar de luxo da sociedade. O autor transitou por ambos, e de uma ponta a outra a insatisfação o acompanhou. Ele não se realizava como operário, vagabundo e tampouco como escritor renomado. Sua escrita, que ironicamente ele denominava como atividade de "mercador da inteligência", apresenta inclusive o inconformismo diante das fronteiras que formalmente separam literatura e sociologia, como se ele quisesse escrever uma sociologia não acadêmica, uma espécie de sociologia em linguagem literária, em formato de contos, romances e depoimentos. Nela, categorias muitas vezes descritas pela sociologia de maneira extremamente abstratas e frias, aparecem de forma visceral e pulsante.

\section{Tiras e vagabundos}

O livro A Estrada (2008h), publicado em 1907, foi baseado na viagem que London realizou em 1894 pelos Estados Unidos e Canadá, quando tinha apenas dezoito anos de idade (PERICÁS, 2008). Diferentemente do tipo de migração clássica estudado por Durhan (1973), na qual o trabalhador migra em busca de emprego na cidade, London migrou neste ano como vagabundo itinerante, viajando clandestinamente em trens, a pé e sobrevivendo principalmente de mendicância. Peregrinou em fuga do trabalho, não era um flaneur e tampouco mero observador; era alguém que passava deixando rastros.

O ano de 1894 foi marcado por uma aguda crise econômica nos Estados Unidos. O número de desempregados era altíssimo, chegando ao ponto de parte dessa massa se organizar no formato de exército e marchar para Washington com intuito de pressionar o presidente por geração de empregos. Jack London chegou temporariamente a fazer parte de um desses exércitos, mas saiu antes do mesmo chegar a Washington - como foi dito anteriormente, ele queria muito mais que emprego. A sua participação no exército de Kelly foi retratada no conto intitulado Dois mil vagabundos (2008i).

Dentre outros aspectos da viagem, vale mencionar sua prisão, ocorrida próximo às Cataratas do Niágara. A acusação era por vadiagem. Sem direito à defesa, foi condenado a 30 dias de prisão numa penitenciária. Essa história foi descrita nos contos “Grampeado” (2008j) e A Penitenciária (2008k). Mas não nos deteremos nos pormenores desses textos, pois é a relação dos vagabundos com os policiais o que mais nos interessa.

No conto Tiras (LONDON, 20081), são relatados vários momentos em que foi perseguido por policiais e inicia fazendo uma análise da relação dos tiras com os vagabundos: 


\section{Lúcio Vasconcellos de Verçoza}

Se os vagabundos desaparecessem subitamente dos Estados Unidos, isso resultaria em grande sofrimento para muitas famílias em todo país. O vagabundo permite que centenas de homens ganhem a vida de forma honesta, eduquem seus filhos e os criem laboriosos e tementes a Deus. Bem sei disso. Em certa época, meu pai era policial e caçava vagabundos para viver. A comunidade o pagava por cabeça, por tantos vadios que pudesse pegar; ele também recebia, creio eu, pagamentos pelas viagens. A sobrevivência foi sempre um problema premente em nosso lar, e a quantidade de carne na mesa, o novo par de sapatos, um dia de passeio ou o livro escolar dependiam da sorte que meu pai tivesse na perseguição. [...], mas tudo isso faz parte do jogo. $\mathrm{O}$ vagabundo desafia a sociedade, e os cães de guarda da sociedade vivem dele. Alguns vadios gostam de ser pegos pelos cães de guarda - em especial no inverno. É claro, estes selecionam comunidades onde as cadeias são "boas", onde não há trabalho obrigatório e onde a comida é farta. Também havia (e provavelmente ainda há) policiais que dividiam seus honorários com os indivíduos que prendiam. Tal guarda não precisa caçar. Ele apita e a caça vem direto para suas mãos. É surpreendente o dinheiro que é feito com vagabundos sem um tostão no bolso. Por todo o Sul - pelo menos quando eu estava nessa vida - existem campos de prisioneiros e plantações onde o tempo dos condenados é comprado pelos fazendeiros e onde o vagabundo simplesmente tem que trabalhar. (LONDON, 20081, p. 173-174).

O autor revela com ironia e de maneira praticamente etnográfica a relação dos policiais com os vagabundos. Apesar do contexto distinto, podemos estabelecer um paralelo entre sua abordagem e a forma como Foot Whyte (2005), décadas depois, analisou a relação entre os policiais e os gângsteres - no livro Sociedade de esquina. Em ambos, é sublinhada a relação de dependência entre o legal e o ilegal, entre o Estado e sua margem. Nas duas perspectivas, o ilegal (vagabundo e gângster) deve ser visto não como algo necessariamente dissociado ou contrário ao Estado, mas a partir das relações permanentes que ambos estabelecem. Esse pressuposto de fronteira borrada entre o lícito e o ilícito está presente, com grande ênfase, em autores da sociologia urbana contemporânea, como nos trabalhos de Feltran (2012), Telles e Hirata (2007). London antecipou essa perspectiva analítica por meio de uma espécie de sociologia literária da experiência vivida.

\section{No limiar entre a sociologia e a literatura}

As linhas textuais de London são peregrinas, assim como nos romances de Graciliano Ramos, elas perambulam pela fronteira entre a confissão e a ficção 
(CANDIDO, 1992). Seus contos estão na borda entre o real e o imaginário, são testemunhos e, ao mesmo tempo, imaginação. London faz uma literatura que inventa sociologia, e uma sociologia que invade a arte literária. Ele cria uma escrita que tensiona os limites desses dois campos.

Nos contos de London, existe uma sociologia despida do linguajar acadêmico, as categorias se movimentam nuas (sem os trajes do suposto rigor). Nem por isso seus escritos se resumem exclusivamente a descrições do real, há neles um inconformismo permanente diante da realidade - e talvez essa seja a chave para compreender o potencial analítico presente em seus contos. Não se trata de uma sociologia livresca, mas de uma sociologia insólita. Uma forma de sociologia sem notas de rodapé, mas repleta daquilo que Gabriel Antunes (2009, p. 75) chamaria de notas de meio-fio: "feitas a partir da dobra entre o chão que suporta os movimentos e a vida comum da cidade" e, para além das notas de meio-fio, há ainda inúmeras notas de pé de montanha e de beira da estrada.

\section{LABOR, VAGRANCY AND ANTI-CAPITALISM: AN ESSAY ABOUT JACK LONDON'S NONCONFORMIST SOCIOLOGY}

ABSTRACT: Jack London's work is filled with references to his experiences living as a working-class child, a freshwater pirate, a nomadic hobo, a socialist militant as well as many other controversial facets of who he was. These are recurrent themes in his writing. This essay investigates how London approaches some of these themes and suggests that in his tales, literary art mingles with an unusual form of sociology.

KEYWORDS: Literary Art. Sociology. Anti-capitalism.

\section{REFERÊNCIAS}

ANTUNES, Gabriel Silveira de Andrade. Filosofias com cotidiano: andanças filosóficas. Brasília: Bibliofonte, 2009.

BAKERS, Marcelo. Prefácio. In: Franz Kafka. Carta ao Pai. Porto Alegre: L\&PM Pocket, 2004.

BOURDIEU, Pierre. A ilusão biográfica. In: AMADO, Janaina; FERREIRA, Marieta M. (Org.). Usos e abusos da história oral. Rio de Janeiro: Fundação Getúlio Vargas, 2006.

CANDIDO, Antônio. Ficção e confissão: ensaios sobre Graciliano Ramos. São Paulo: Editora 34, 1992. 
DURHAN, Eunice. A caminho da cidade: A vida rural e a migração para São Paulo. São Paulo: Editora Perspectiva, 1973.

FELTRAN, Gabriel de Santis. Governo que produz crime, crime que produz governo: o dispositivo de gestão do homicídio em São Paulo (1992-2011). Revista Brasileira de Segurança Pública, v. 6, p. 232-255, 2012.

GEBRIM, Magda Lopes. Apresentação. In: LONDON, Jack. Jack London contos. São Paulo: Expressão Popular, 2008.

KAFKA, Franz. Carta ao Pai. Porto Alegre: L\&PM Pocket, 2004.

LONDON, Jack. O chamado da Floresta. São Paulo: Editora Ática, 1995. . Caninos Brancos. São Paulo: Martin Claret, 2001.

. O Tacão de Ferro. São Paulo: Boitempo Editorial, 2002.

. Pé na Estrada. In: LONDON, Jack. A Estrada. São Paulo: Boitempo, 2008a.

. O que a vida significa para mim. In: LONDON, Jack. Jack London contos. São Paulo: Expressão Popular, 2008b.

. O herege. In: LONDON, Jack. Jack London contos. São Paulo: Expressão Popular, 2008c.

. Ao sul da fenda. In: LONDON, Jack. Jack London contos. São Paulo: Expressão Popular, 2008d.

. Fazer uma fogueira. In: LONDON, Jack. Jack London contos. São Paulo: Expressão Popular, 2008e.

. Como me tornei socialista. In: LONDON, Jack. Jack London contos. São Paulo: Expressão Popular, 2008f.

. Amor à vida. In: LONDON, Jack. Jack London contos. São Paulo: Expressão Popular, 2008g.

. A Estrada. São Paulo: Boitempo, 2008h.

. Dois mil vagabundos. In: LONDON, Jack. A Estrada. São Paulo: Boitempo, $2008 \mathrm{i}$.

. "Grampeado". In: LONDON, Jack. A Estrada. São Paulo: Boitempo, 2008j.

. A penitenciária. In: LONDON, Jack. A Estrada. São Paulo: Boitempo, 2008k.

. Tiras. In: LONDON, Jack. A Estrada. São Paulo: Boitempo, 20081

MARX, Karl. O Capital: crítica da economia política. Rio de Janeiro: Bertrand Brasil, 1989. 
MARINI, Ruy Mauro. Dialética da dependência. In: STEDILE, João Pedro; TRANSPADINI, Roberta (Org.). Rui Mauro Marine vida e obra. São Paulo: Expressão Popular, 2005.

PERICÁS, Luís Bernardo. Jack London na Estrada. In: LONDON. Jack. A Estrada. São Paulo: Boitempo, 2008.

PIERUCCI, Antônio Flávio. Apresentação. In: WEBER, Max. A ética protestante e o espírito do capitalismo. São Paulo: Companhia das Letras, 2004.

SIMMEL, Georg. A metrópole e a vida mental. In VELHO, Otávio (Org.) O Fenômeno Urbano. Rio de Janeiro: Zahar Editor, 1977.

TELLES, Vera da Silva; HIRATA, Daniel Veloso. Cidade e práticas urbanas: nas fronteiras incertas entre o ilegal, o informal e o ilícito. Estudos Avançados, São Paulo, v. 21, n. 61, p. 173-191, 2007.

WEBER, Max. A Ética Protestante e o Espírito do Capitalismo. São Paulo: Companhia das Letras, 2004.

WHYTE, William Foote. Sociedade de esquina. Rio de Janeiro: Jorge Zahar, 2005.

Recebido em 04/02/2018.

Aprovado em 18/04/2018. 
